\title{
A função social do Programa Saúde na Escola: formação para a nova sociabilidade do capital?
}

\author{
Aline Fabiane Barbieri * \\ Amélia Kimiko Noma **
}

\begin{abstract}
Resumo
Analisa-se a função social do Programa Saúde na Escola (PSE) com base em estudo de caráter bibliográfico e documental, alicerçado no método materialista histórico. Identifica-se que o PSE está articulado a três componentes do projeto educacional neoliberal de Terceira Via: a noção de "sociedade civil ativa" e o projeto do "Terceiro Setor", a ideologia do "capital social" e a teoria do "capital humano". Afirma-se que a função social do PSE é colaborar com a disseminação da racionalidade ideológica conservadora, compatível com a edificação de um novo padrão de sociabilidade no Brasil, via formação de subjetividades ativas em saúde, bem como atuar na amenização das expressões da "questão social" e manutenção da força de trabalho apta a atender às necessidades de exploração capitalista.
\end{abstract}

Palavras-chave: Políticas públicas em educação. Política de saúde. Programa de Atenção à Saúde do Escolar.

\footnotetext{
* Doutora em Educação pela Universidade Estadual de Maringá (UEM). Professora do Instituto Federal de Educação, Ciência e Tecnologia de Santa Catarina (IFPR) - Campus Pitanga.

*** Doutora em História pela Pontifícia Universidade Católica de São Paulo (PUC-SP). Professora do Departamento de Fundamentos da Educação da Universidade Estadual de Maringá (UEM).
} 


\section{Introdução}

Objetiva-se apreender os pilares teóricos centrais do Programa Saúde na Escola - que está articulado com as políticas públicas brasileiras de educação e saúde na escola - com o intuito de analisar a função social dessa política. Trata-se de programa instituído pelo governo de Luiz Inácio Lula da Silva (Partido dos Trabalhadores - PT) em 2007, com a promulgação do Decreto $n^{\circ}$ 6.286, de 5 de dezembro de 2007, com o propósito de contribuir para a garantia dos direitos sociais à saúde e à educação dos estudantes da rede pública de educação básica por meio de ações de prevenção, promoção e atenção à saúde.

O conteúdo aqui apresentado alicerça-se em pesquisa de caráter documental e bibliográfica desenvolvida com base em análise de documentos. As fontes primárias examinadas foram documentos oriundos dos campos das políticas de educação e de saúde.

Adota-se o materialismo-histórico como referencial teórico e metodológico para a interpretação da realidade e para a abordagem do objeto em investigação. Para sua efetivação, são utilizadas as seguintes categorias analíticas: práxis, totalidade, contradição, mediação, hegemonia e reprodução. A categoria da práxis, conforme Netto e Braz (2006), engloba as diversas objetivações humanas. Por essa razão, a utilização dessa categoria justifica-se por sua compreensão das políticas como parte do mundo social construído e constantemente reconstruído pelos homens. Por isso, as políticas públicas abordadas não são aqui entendidas e analisadas enquanto particularidades isoladas do todo social.

Considerando a totalidade como categoria teórico-ontológica basilar, os documentos de políticas são analisados como singularidades que se relacionam dialeticamente com totalidades mais amplas do modo de produção social. Para que os múltiplos determinantes do objeto de pesquisa sejam explicitados, suas fontes são entendidas como particularidades a serem articuladas a uma totalidade histórica, o que evidencia o importante papel desempenhado pela categoria da mediação neste estudo. Ademais, a categoria da mediação exerce papel fundamental para a realização do processo investigativo, dada a necessidade de se descobrirem as relações existentes entre os complexos e as singularidades que compõem a totalidade (NETTO, 2011). A adoção dessa categoria subsidia a articulação entre os aspectos singulares e universais desta pesquisa, não permitindo o tratamento e análise dos documentos de políticas como particularidades isoladas.

Considerando-se que a categoria da hegemonia está relacionada à busca pelo estabelecimento e manutenção do consenso e formação do senso comum, essenciais à manutenção da direção cultural e 
ideológica exercida pela classe dominante ou por frações dessa classe no poder, e considerando-se que o Programa Saúde na Escola veicula conceitos que corroboram com a formação desse consenso, entende-se que a utilização da categoria hegemonia encontra justificativa neste estudo. Assim, tendo-se em vista que o Programa Saúde na Escola pode estar servindo como mediador ao processo de produção e reprodução de conceitos e valores necessários à manutenção desse modo de organização política da sociedade, a utilização da categoria da reprodução também se justifica neste estudo, partindo-se do pressuposto de que ela diz respeito à tendência existente em todos os modos de produção à autoconservação do sistema social vigente, por meio de suas instituições específicas (CURY, 1986).

No âmbito das políticas públicas internacionais de educação e saúde na escola, foram analisados documentos divulgados por agências do sistema Organização das Nações Unidas (ONU), tais como declarações, cartas, informes e relatórios, relacionados ao campo da educação, da saúde e da educação e saúde. No domínio das políticas nacionais, as fontes analisadas foram documentos de políticas de educação, de políticas de saúde e de políticas de educação e saúde na escola. Analisam-se documentos elaborados e publicados pelo Ministério da Educação (MEC) em conjunto com outros órgãos nacionais e agências internacionais. Dentre estes, constam documentos normativos e orientadores da política educacional brasileira, como leis, planos, parâmetros e diretrizes.

Em consonância ao método adotado, para analisar o objeto em estudo, utiliza-se o procedimento de articular a discussão das questões abordadas com o contexto histórico no qual o objeto se constituiu. O procedimento justifica-se por considerar que as políticas em foco são expressões de ações e estratégias de políticas públicas pautadas num novo padrão político-ideológico de respostas às manifestações da "questão social", constituído na transição do século XX para o XXI. Tais políticas estão relacionadas a mecanismos corretivos e controladores de todo o sistema social para a manutenção contínua do sociometabolismo do capital no processo de crise estrutural pelo qual atravessa e das mudanças político-econômicas dela resultantes.

Nesse sentido, aborda-se a crise estrutural do capital e as novas formas de regulação social dela advindas. De forma mais específica, trata-se do neoliberalismo de Terceira Via, como parte da estratégia capitalista contemporânea de desenvolvimento e dominação das classes subalternas, e da forma como o Programa Saúde na Escola vem atuando no âmbito do seu projeto educacional. 


\section{A crise estrutural do capital e as novas formas de regulação social}

Como reação à crise estrutural do capital, novas formas de regulação e conformação ideológica passaram a ser empreendidas para a conservação das políticas favoráveis à reprodução do capital e à manutenção da hegemonia das classes e frações de classes, corroborando com a consolidação dos grandes grupos econômicos produtivos e financeiros.

Para proporcionar a retomada das taxas de crescimento e lucratividade, bem como a estabilidade política ao capital, frente ao fracasso do neoliberalismo de formato clássico, uma nova estratégia de desenvolvimento e dominação das classes subalternas precisou ser engendrada, com uma política mais estável e de longo prazo. Na década de 1990, houve a reformulação do ideário neoliberal, com vistas a reestabelecer as estratégias de coesão e regulação social compatíveis com a manutenção da hegemonia burguesa. Um dos resultados desse processo de reformulação foi o neoliberalismo de Terceira Via.

Propondo a articulação entre economia de mercado e justiça social, a Terceira Via almeja uma recuperação do projeto burguês que, por um lado, mantém as premissas básicas do liberalismo e, por outro, retoma os elementos centrais do reformismo da socialdemocracia. Pelo fato de propor a combinação entre os fundamentos econômicos do neoliberalismo ortodoxo - tais como a defesa do individualismo metodológico, a exaltação das virtudes do mercado e do Estado de Direito - e valores como solidariedade e participação social, a Terceira Via pode ser compreendida como um “neoliberalismo humanizado".

O movimento revisionista fomentou concomitantemente a reforma do aparelho do Estado um processo de "[...] reeducação política das massas - isto é, aprimoramento da sociabilidade neoliberal -, visando à consolidação de um suposto modelo capitalista de 'face humana' e um conformismo capaz de assegurar a coesão social em torno desse modelo redefinido” (MARTINS, 2009, p. 61). Nesse contexto, a reeducação da população tornou-se necessária para a efetivação da nova forma de relacionamento entre sociedade civil, Estado e mercado arquitetada pelo neoliberalismo de Terceira Via.

Para operacionalizar esse processo de reeducação das massas - voltado à edificação do novo padrão de sociabilidade - é que se funda o projeto educacional do neoliberalismo de Terceira Via, denominado por Neves (2005, p. 15) de "nova pedagogia da hegemonia". A "nova pedagogia da hegemonia" refere-se, portanto, ao projeto educativo burguês contemporâneo, fundamentado nos preceitos do neoliberalismo de Terceira Via, que objetiva contribuir com a construção de um novo 
padrão de sociabilidade por meio da formação de novas subjetividades demandadas pelo sociometabolismo do capital.

A repolitização da sociedade civil é a via adotada pelo projeto neoliberal da Terceira Via para o estabelecimento de um novo contrato social, a partir da criação de sujeitos políticos e novas subjetividades "[...] com as tarefas de assumir as responsabilidades sociais até então restritas à aparelhagem estatal, eliminar as resistências sociais à ordem burguesa e disseminar valores caros a essa doutrina" (NEVES, 2005, p. 16). A construção da nova racionalização ideológica - a que se presta o projeto educacional do neoliberalismo de Terceira Via ou a "nova pedagogia da hegemonia" - é guiada pela necessidade de formação de sujeitos ativos e autônomos, adaptados ao novo contrato social caracterizado pelo afastamento do Estado no oferecimento dos serviços sociais.

Se, como afirma Behring (2007, p. 172), a “[...] onda longa com tendência à estagnação coloca a política social no cerne da crise", na transição do século XX para o XXI, a política social passa a ser concebida como estratégia econômica e política de controle do metabolismo social e de regulação social. Nessa perspectiva, as políticas sociais são um dos instrumentos pelos quais o Estado vem exercendo seu papel educador na legitimação e produção de consensos (NEVES, 2008). O que significa afirmar que as "[...] políticas sociais do Estado capitalista monopolista passaram a desempenhar um importante papel na legitimação do padrão de sociabilidade capitalista, ainda que em seu conteúdo contemplassem contraditoriamente demandas da classe trabalhadora" (MARTINS, 2009, p. 18). Tal argumentação permite compreender as políticas sociais contemporâneas como instrumentos de difusão da "nova pedagogia da hegemonia" e, desse modo, de constituição do novo padrão de sociabilidade e reconstrução da hegemonia burguesa.

É nesse sentido que se compreende o Programa Saúde na Escola (PSE), como parte do projeto educacional burguês contemporâneo e, por decorrência, como um instrumento de difusão da "nova pedagogia da hegemonia". Como agente de construção da nova sociabilidade, entende-se que o PSE ajuda a disseminar essa nova pedagogia na medida em que atua na formação de novas subjetividades, protagonistas e ativas em saúde e, por extensão, ajustadas aos delineamentos dispostos pelo novo contrato social neoliberal de Terceira Via. Sendo assim, o PSE pode ser incluído no conjunto das "[...] políticas educacionais neoliberais que se prestam à formação ético-política do intelectual urbano de novo tipo [...]" (NEVES, 2005, p. 105).

Argumenta-se que o fato de as políticas públicas e sociais oriundas do novo Estado educador (GROPPO; MARTINS, 2008) terem sido postas, fundamentalmente, para atuar na regulação social e disseminação dos preceitos da "nova pedagogia da hegemonia", não deve ser entendido como 
indicativo de que tais políticas somente possam transmitir componentes da ideologia dominante. O caráter não absoluto e nem linear com que a determinação econômica atua sobre os diversos complexos sociais permite compreender as políticas como fenômenos sociais estruturalmente contraditórios e detentores de certa autonomia relativa perante os determinantes de ordem econômica capitalista. Faz-se necessária a relativação da afirmativa de que o PSE transmite unicamente os preceitos da "nova pedagogia da hegemonia" e, portanto, os elementos direcionados à construção do novo padrão de sociabilidade burguesa. As políticas de educação e saúde na escola exercem papel de importância na luta pela conquista e efetivação de direitos sociais, em especial de educação e saúde, e para a melhoria das condições de vida da classe trabalhadora.

Na sequência, aborda-se o Programa Saúde na Escola com vistas a apresentar os principais pontos de compatibilidade entre este e os preceitos da "nova pedagogia da hegemonia" e também revelar a função social que o PSE vem exercendo no atual momento do sociometabolismo capitalista.

\section{O Programa Saúde na Escola (PSE)}

O Programa Saúde na Escola está estruturado em três grandes componentes que devem ser articulados ao Projeto Político-Pedagógico (PPP) das escolas: Avaliação clínica e psicossocial, Promoção e prevenção da saúde e Formação (BRASIL, 2011a). A implementação do PSE nas cidades ocorre via adesão dos municípios aos objetivos e diretrizes do programa. Os municípios interessados precisam registrar manifestação de interesse e apresentar um projeto Municipal de Saúde na Escola ao MEC e ao Ministério da Saúde (MS), no qual devem estar contidas as metas e estratégias do município para as ações de educação e saúde para a cidade (BRASIL, 2010).

Na dinâmica do PSE, o compromisso entre município e governo federal é firmado mediante a assinatura do Termo de Compromisso pelos Secretários Municipais da Saúde e da Educação e mediante a inserção do Projeto municipal no Sistema Integrado de Monitoramento, Execução e Controle (SIMEC). Trata-se de documento no qual constam as ações a serem implementadas; nele estipula-se que "[...] escolas e equipes de Atenção Básica participarão do programa, bem como as metas de cobertura de educandos para as ações de promoção, prevenção, educação e avaliação das condições de saúde no território de responsabilidade" (BRASIL, 2013b, p. 77). O estabelecimento do Termo de Compromisso Municipal como instrumento para o recebimento de recursos financeiros do PSE ocorreu com a publicação da Portaria interministerial n 1.910 , de 08 de agosto de 2011. 
Uma vez tendo aderido ao PSE, as Secretarias Municipais de Educação e Saúde passam a receber kits com material clínico e pedagógico para o desenvolvimento das atividades previstas pelo Programa. Em contrapartida, os municípios devem formar Grupos de Trabalho Intersetoriais (GTI), que têm a incumbência de realizar um mapeamento da rede do Sistema Único de Saúde (SUS), de Atenção Básica, do Plano de Saúde da Família (PSF) e sua respectiva Equipes de Saúde da Família (ESF) e da rede de ensino existente na cidade. Além disso, o GTI tem a função de elaborar um diagnóstico das necessidades da cidade e definir as atribuições das ESF e das escolas em cada uma das suas regiões (BRASIL, 2011a).

O PSE é desenvolvido por meio de visitas permanentes das ESF às escolas participantes. Nessas ocasiões, são realizadas intervenções com vistas a: a) avaliar as condições de saúde dos educandos; b) elaborar ações conjuntas entre as ESF e a comunidade escolar e c) promover ações de educação permanente em saúde, atividade física e capacitação profissional para o monitoramento da saúde dos estudantes. Na dinâmica do PSE, o financiamento é efetuado via Ministério da Saúde, que repassa a verba ao Programa Saúde da Família. O MEC participa com o oferecimento de materiais pedagógicos para o Programa. Prevê-se repasse de $70 \%$ do valor total do recurso financeiro destinado ao PSE imediatamente após a assinatura do Termo de Compromisso pelo município, enquanto os 30\% restantes são pagos após o cumprimento de $70 \%$ das metas firmadas ${ }^{3}$ (VIEIRA; VIEIRA, 2011; BRASIL, 2011a).

A verificação do cumprimento das metas do PSE pelos municípios é realizada por meio do SIMEC, que deve ser alimentado a cada seis meses (BRASIL, 2011a). Outro instrumento de acompanhamento do desenvolvimento das atividades do PSE é a Comissão Intersetorial de Educação e Saúde na Escola (CIESE). Essa Comissão é responsável, portanto, por formular a Política de Educação e Saúde na Escola, bem como por acompanhar as atividades do PSE, especialmente quanto ao material elaborado para a utilização no Programa.

Informa Vieira (2013) que, até 2013, 85,67\% dos municípios brasileiros já haviam assinado o Termo de Compromisso. Até a publicação da Portaria no 1.413/2013, a adesão dos municípios ao PSE estava condicionada à área de abrangência das ESFs, aos indicadores de vulnerabilidade no âmbito da educação, no caso, o Índice de Desenvolvimento da Educação Básica (IDEB), e à adesão ao Programa Mais Educação (BRASIL, 2007). Progressivamente, os critérios de adesão ao PSE foram diminuindo, até serem extintos em definitivo no ano de 2013, um dos principais motivos pelo fato de a adesão ao Programa nesse ano ter praticamente dobrado em relação aos anos de 2011 e 2012. 
A perspectiva é a de que o PSE se expanda ainda mais nos próximos anos. Sua proposta tem plena compatibilidade com os Objetivos de Desenvolvimento do Milênio (ODM), iniciativa da ONU lançada em 2000. Dentre os pontos de conexão entre o PSE e os ODM, pode-se fazer alguns destaques: a) Entre as políticas sociais desenvolvidas no Brasil com base no primeiro Objetivo do Milênio Erradicar a extrema pobreza e a fome -, o Programa Saúde na Escola é, atualmente, apontado como uma das principais iniciativas do governo voltada às crianças, aos adolescentes e aos jovens; b) O PSE está inserido na agenda de melhoria da qualidade da educação básica e, portanto, atua em consonância com o Objetivo número 2 - Educação Básica de qualidade para todos; c) Desde 2013, o PSE passou a ser desenvolvido em centros de Educação Infantil, o que o colocou em sintonia com o Objetivo número 4 - Reduzir a mortalidade infantil; d) O Objetivo número 6 - Combater o HIV/AIDS, a malária e outras doenças - está diretamente relacionado ao PSE, mais especificamente ao componente II do Programa, "Promoção da Saúde e Prevenção", no qual estão inseridas as ações do Projeto Saúde e Prevenção nas Escolas (SPE); e) O PSE também está relacionado ao Objetivo número 7 - "Qualidade de vida e respeito ao meio ambiente", mais especificamente no Componente II do PSE, "Promoção da Saúde e Prevenção"; f) As iniciativas relativas à Política Nacional de Alimentação Escolar (PNAE), integrada à proposta do PSE, são apoiadas no item Acesso à alimentação das Metas de Desenvolvimento do Milênio.

O PSE está previsto na agenda do "Plano de Ações Estratégicas para o Enfrentamento das Doenças Crônicas não Transmissíveis (DCNT) no Brasil 2011-2022”, publicado pelo Ministério da Saúde em 2011. Nesse documento, a articulação entre educação e saúde é exaltada, considerando os altos índices de doenças crônico-degenerativas existentes e pelo fato de estas estarem relacionadas a um conjunto de comportamentos adotados desde tenra idade. Dentre as 11 metas citadas, sete estão relacionadas diretamente ao PSE. Por isso, a ampliação do PSE aparece como uma das principais ações a serem desenvolvidas a partir do eixo da "Atividade Física” deste documento (BRASIL, 2011b).

O PSE insere-se na agenda do "Plano Brasil Sem Miséria", instituído em 2011, por meio do Decreto $n^{\circ}$ 7.492/11. Tem como objetivo superar a situação de extrema pobreza da população brasileira, por meio da integração e articulação de políticas, programas e ações (BRASIL, 2011c). Nesse Plano, o PSE está incluído no eixo de atuação “Acesso a Serviços”, como uma das frentes de ações no combate à miséria no Brasil. Todavia, é importante destacar que, mesmo antes da inclusão do PSE neste Plano, o Programa já pretendia contribuir nesse combate, como se pode observar em um de seus documentos orientadores: “O apoio institucional dos Estados aos municípios é imprescindível para 
o avanço na implementação do PSE no Brasil e qualificação da saúde e da educação, contribuindo para a superação da miséria no nosso país.” (BRASIL, 2011a, p. 9).

\section{O PSE como instrumento de difusão da "nova pedagogia da hegemonia"}

Com base nas fontes consultadas neste estudo, entende-se que as políticas de educação e saúde na escola atuam no compartilhamento dos preceitos da "nova pedagogia da hegemonia" que, com base na reformulação de conceitos e criação de consensos, vem empreendendo uma reeducação política sobre as massas com o objetivo de atender às novas necessidades do setor produtivo e de alterar a correlação de forças dos projetos em disputa. Os principais pontos de conexão identificados entre a "nova pedagogia da hegemonia" e as políticas nacionais e internacionais de educação e saúde na escola são: o incentivo à formação da "sociedade civil ativa" e do "Terceiro Setor", a promoção do "capital social" e o compartilhamento dos princípios da teoria do "capital humano". A identificação desses pontos de conexão evidencia a participação efetiva das políticas de educação e saúde na escola, principalmente o Programa Saúde na Escola, no trabalho de educação da nova sociabilidade para o capital.

\section{Incentivos à formação da "sociedade civil ativa" e do "Terceiro Setor" no PSE}

Embora o neoliberalismo de Terceira Via discurse em prol da construção de um novo contrato social baseado em um sistema de oferecimento de serviços sociais cujo pilar central seja a articulação entre comunidade, empresariado e Estado, na prática, defende que a maioria dos serviços sociais seja oferecido pela "sociedade civil ativa", de forma a deixar o Estado com o menor número possível de tarefas sociais. Por meio do incentivo à participação ativa da sociedade civil, especialmente no âmbito da resolução dos conflitos sociais, o objetivo seria a formação do que Giddens (1998) denomina de "sociedade civil ativa", elemento basilar para a efetivação do novo contrato social de Terceira Via.

Compreendida como sinônimo de "Terceiro Setor" (MARTINS, 2009), a "sociedade civil ativa" refere-se a grupos da sociedade civil capacitados a se organizarem autonomamente para o enfrentamento de problemas sociais locais, com base no trabalho voluntário (MONTAÑ; DURIGUETTO, 2011). Nessa perspectiva, Martins (2009, p. 60) assinala que as forças neoliberais passaram a reconhecer a participação popular como “[...] articuladora da nova sociabilidade e não 
como um fenômeno nocivo a ser contido, ou mesmo reprimido, como recomendado pelo pensamento hayekiano ortodoxo e praticado por vários governos eleitos pelo voto popular no centro e na periferia".

O projeto do "Terceiro Setor", explicam Montaño e Duriguetto (2011, p. 305), foi fomentado e expandido a partir da década de 1990, com base na "satanização do Estado interventor" somada à "santificação da sociedade civill". Isso porque é propalado que a atuação do "Terceiro Setor" se sustentaria na suposta ineficiência administrativa do Estado e, paralelamente, na eficiência da sociedade civil. Enquanto o Estado seria visto como instituição burocrática e ineficiente, as organizações do "Terceiro Setor" seriam dinâmicas, flexíveis, participativas e eficientes no atendimento às demandas sociais. Esses argumentos servem de justificativas para a redução do papel do Estado no oferecimento dos serviços sociais e para o desenvolvimento do "Terceiro Setor" (MONTAÑO, 2002).

O projeto do "Terceiro Setor" se desenvolve em um contexto de crise estrutural do capital caracterizado pela mercadorização das políticas sociais e pela ofensiva aos direitos sociais, somada ao fomento do voluntariado. Para cobrir as lacunas deixadas pelo distanciamento do Estado da oferta de serviços sociais, "[...] parcelas importantes das respostas à 'questão social' são privatizadas e transferidas ao mercado (quando lucrativas) e à 'sociedade civil' ou 'terceiro setor' (quando deficitárias), que vende ou fornece 'gratuitamente' os serviços sociais” (MONTAÑO, 2002, p. 55).

Em um quadro social de potencialização das expressões da questão social, em que amplos setores populacionais não têm acesso a serviços sociais básicos, transfere-se à sociedade civil a tarefa de assistir tais setores "[...] mediante práticas voluntárias, filantrópicas e caritativas, de ajuda-mútua ou de auto-ajuda [sic]" (MONTAÑO, 2002, p. 56). Neste espaço, surge "[...] o 'terceiro setor', atendendo a população 'excluida' ou parcialmente 'integrada"' (MONTAÑO, 2002, p. 56, grifos do autor).

Com vistas a incentivar a formação da "sociedade civil ativa", programas e políticas de corte neoliberal tendem "[...] a instrumentalizar um conjunto de valores, práticas, sujeitos, instâncias: o chamado 'Terceiro Setor', os valores altruístas de 'solidariedade individual' e do 'voluntarismo' e as instituições e organizações que em torno deles se movimentam" (MONTAÑO, 2002, p. 58). Além disso, a formação do cidadão ativo - sujeito que age menos na reivindicação de direitos e mais na prestação de serviços sociais - permite entrever a intenção de promover a "[...] colaboração entre classes e harmonização, nas quais os voluntários das organizações não-governamentais [sic] são exemplos ideais. Este incentivo à participação cidadã colaborativa é um dos principais elementos desta recriação da 'sociedade civil' [...]”' (GROPPO; MARTINS, 2008, p. 224). 
Observa-se, assim, que o Estado "[...] dirigido pelos governos neoliberais, se afasta parcialmente da intervenção social, porém, ele é subsidiador e promotor do processo ideológico de 'transferência' da ação social para o 'terceiro setor'”, com vistas a amenizar e minimizar os impactos sociais das investidas neoliberais (MONTAÑO, 2002, p. 59, grifos do autor). Desse modo, “[...] enquanto para Gramsci a sociedade civil é a principal arena de luta de classes nas sociedades 'ocidentais' [...]', para a Terceira Via, o conceito de sociedade civil deveria ser atrelado ao de filantropia e voluntariado (NEVES, 2005, p. 12).

Frente ao exposto, “[...] fica evidente que o programa da Terceira Via deseja construir uma nova sociabilidade em que predominariam organizações sociais, operando nos níveis mais elementares da consciência política coletiva” (MARTINS, 2009, p. 84). Sua missão seria a educação das massas para uma nova dinâmica social na qual haveria uma mudança no Estado. Este, por sua vez, deixaria de ser “protetor" e passaria a ser “[...] o indutor do 'progresso' e cada um, de receptor dos bens sociais e culturais, tornar-se-ia o empreendedor de seu próprio sucesso (ou fracasso) a partir da liberdade de escolhas e autonomia para agir" (MARTINS, 2009, p. 84).

Para os ideólogos da Terceira Via, a intenção seria forjar uma nova forma de sociabilidade na qual as soluções para os problemas sociais (como os relacionados à saúde) fossem obtidas mediante a participação da sociedade civil, e não necessariamente por medidas governamentais. Dito de outro modo, o neoliberalismo de Terceira Via propõe que “[...] a 'sociedade civil ativa', na qual estariam incluídas as empresas, assuma responsabilidades para definição de uma rede de proteção social descentralizada e desvinculada do Estado" (MARTINS, 2009, p. 80).

Em face da importância da formação da "sociedade civil ativa" e do "Terceiro Setor" para a constituição do contrato social burguês contemporâneo, o incentivo à participação ativa da população é um dos pontos centrais do processo de reeducação política dos cidadãos e de renovação do padrão cultural da sociabilidade, bem como um dos principais pontos de interconexão entre a "nova pedagogia da hegemonia" e a política nacional de educação e saúde na escola. Isso porque a valorização da participação ativa dos sujeitos nas ações em saúde é corrente no discurso das políticas de educação e saúde na escola, como pode ser identificado no principal documento orientador do PSE (BRASIL, 2011a, p. 15), quando se afirma que, como produção social, a saúde "[...] exige a participação ativa de todos os sujeitos na construção de ações que visam às escolhas mais saudáveis".

Na perspectiva do incentivo à participação ativa em saúde e à formação da "sociedade civil ativa", no Programa Saúde na Escola, identifica-se a proposta de empoderamento da população intra e extraescolar. Por isso, no âmbito do referido Programa, entende-se que, nas escolas, "[...] o trabalho de 
promoção da saúde com os educandos, e também com professores e funcionários, precisa ter como ponto de partida 'o que eles sabem' e 'o que eles podem fazer'” (BRASIL, 2011a, p. 6). Isso seria fundamental para "[...] desenvolver em cada um a capacidade de interpretar o cotidiano e atuar de modo a incorporar atitudes e/ou comportamentos adequados para a melhoria da qualidade de vida" (BRASIL, 2011a, p. 6).

No horizonte do PSE, a escola é entendida como um espaço privilegiado para a educação e a saúde, valioso para a construção de indivíduos e comunidades ativas - responsáveis, conscientes e protagonistas de suas próprias condições de vida e saúde. Por isso, o PSE propõe o alargamento do papel da instituição escolar no processo de atendimento, prevenção e educação em saúde, visando a contribuir para a melhoria da qualidade de vida da população brasileira por meio da educação para a cidadania e saúde (BRASIL, 2007; BRASIL, 2011a).

No âmbito do PSE, a escola é entendida como espaço fundamental para a produção social da saúde, por conta de sua capacidade de desenvolver sujeitos ativos e comprometidos com valores de cidadania. Assim, as ações de educação e saúde na escola deveriam ser desenvolvidas na perspectiva de construir uma "[...] escola que forme cidadãos críticos e atualizados com habilidades para agir em defesa da vida e de sua qualidade e que, além disso, devem ser compreendidos pelas equipes de Saúde da Família (ESF) em suas estratégias de cuidado" (BRASIL, 2011a, p. 5).

O objetivo volta-se, então, para a oferta de atendimento integral ao educando, envolvendo, dessa forma, atividades de promoção, prevenção, atenção e formação, de maneira a atuar sobre as condições de vulnerabilidade social, potencialmente comprometedoras da aprendizagem, desenvolvimento e permanência do educando na escola. Nesse contexto, busca-se desenvolver ações locais mais sustentáveis, em territórios marcados pela vulnerabilidade. Visando a combater as condições de vulnerabilidade social, o PSE recomenda aos profissionais de educação e de saúde e à comunidade intra e extraescolar que assumam uma atitude para o empoderamento dos princípios básicos da promoção da saúde.

A valorização da participação dos sujeitos e comunidades voltada à formação de indivíduos e grupos ativos também é expressa nas recomendações concernentes à elaboração do projeto municipal do PSE. Compreende-se que o incentivo à participação ativa de sujeitos e comunidades no processo de construção do projeto municipal resulta de uma concepção de "[...] educação que focaliza o sujeito, buscando o desenvolvimento de todas as potencialidades humanas, com equilíbrio entre os diferentes aspectos - cognitivos, afetivos e sociais" (BRASIL, 2010, p. 3). 


\section{A promoção do "capital social" no PSE}

Segundo os preceitos do neoliberalismo de Terceira Via, no lugar de conflitos e lutas de classes, para além da direita e da esquerda, deveria prevalecer a noção de parceria e o espírito de solidariedade, para que a economia pudesse se desenvolver em um contexto de harmonia social. Como complementa Martins (2009, p. 74), ao “[...] invés de tensões e disputas entre classes pelo poder - manifestação típica do 'mundo das polaridades' [...], prevaleceria o colaboracionismo, a responsabilidade social e a liberdade de escolhas individuais". Valores como "justiça social", "liberdade e igualdade de oportunidades", "solidariedade" e "responsabilidade para com os outros" seriam as bases para a formação de "[...] uma geração nova de adultos com espírito empreendedor, iniciativa individual e com senso de responsabilidade social [...]" (MARTINS, 2009, p. 88). A meta seria “[...] tornar o mundo uma comunidade democrática pautada na tolerância e no diálogo entre os indivíduos”, contexto no qual uma das principais funções do governo consistiria, precisamente, em conciliar as reivindicações divergentes de diferentes grupos (MARTINS, 2009, p. 73).

Percebe-se, dessa forma, que tanto para a Terceira Via quanto para o "velho mundo das polaridades", a ideia de classes sociais deveria ser rejeitada, e as diferenças sociais compreendidas como diferenças entre grupos. Nessa linha de pensamento, não haveria mais luta de classes, simplesmente, porque não haveria mais classes sociais. Existiriam apenas indivíduos e grupos com interesses distintos, que deveriam se ajudar mutuamente para a satisfação de suas necessidades (MARTINS, 2009).

É importante destacar ainda que, para a Terceira Via, ao mesmo tempo em que se responsabiliza os sujeitos por suas ações, como se estes agissem individualmente, livres de influências e de determinações sociais, propala-se a necessidade de se alargar a noção de comunidade solidária, de fraternidade para com o próximo e do espírito de solidariedade. A recomendação da Terceira Via seria para que, em situações de resolução de problemas e conflitos, especialmente nas que fossem capazes de poupar a participação estatal, predominasse o sentimento de coletividade e de solidariedade. Em todas as demais situações, dever-se-ia desconsiderar as relações econômicas e políticas que determinam e englobam a totalidade do ser social, adotando-se como parâmetro o sujeito individual, portador de deveres e responsabilidades. Na prática, o real sentido desse novo contrato social seria o de aumentar os deveres e responsabilidades do indivíduo e da sociedade civil, diminuindo, em contrapartida, os deveres e responsabilidades do Estado e do governo para com suas tarefas sociais. 
A mensagem transmitida por meio desses valores e do incentivo à autonomização pessoal seria a de que não somente o Estado deveria se preocupar com o bem-estar da população, mas a sociedade civil como um todo. Assim, em lugar do "[...] associativismo majoritariamente reivindicativo de direitos dos anos 1980”, a Terceira Via propõe o desenvolvimento do associativismo “[...] prestador de serviços sociais de 'interesse público' [...]”, almejando a construção de uma nova cultura cívica pautada na solidariedade e no colaboracionismo (NEVES, 2005, p. 95).

Com isso, torna-se evidente a relação entre os preceitos da "nova pedagogia da hegemonia" e o conceito de "capital social", que ganhou projeção a partir da década de 1990, quando passou a ser evocado no discurso das organizações internacionais, particularmente nos relacionados ao combate à pobreza.

Para Martins (2009), "capital social” seria uma noção indicativa de que o estabelecimento de relações interpessoais pode gerar laços de confiança, solidariedade e de ajuda mútua, fundamentais à capacidade de articulação de grupos para a resolução de problemas imediatos. No discurso das organizações internacionais, os investimentos em "capital social” vêm sendo sustentados na crença de que redes de colaboração promoveriam a cooperação - peça chave para a competição de desenvolvimento econômico e alívio da pobreza. Nota-se, assim, a importância da noção de "capital social" para a efetivação do novo contrato social, compatível com a nova forma do capital de lidar com as manifestações da "questão social".

De acordo com Martins (2007, p. 146), além de ativo, o novo cidadão, segundo a "nova pedagogia da hegemonia", deveria ser reflexivo e possuidor de "[...] espírito empreendedor, capacidade de iniciativa individual e [de] um elevado senso de responsabilidade social comprometido com a busca de soluções para os problemas de sua comunidade”. Groppo e Martins (2008, p. 227), por sua vez, explicam que o papel desempenhado pelo Estado no neoliberalismo de Terceira Via é tomar medidas para enfrentar as manifestações da "questão social" por intermédio de "[...] parcerias com entidades da 'sociedade civil' para, acima de tudo, gestar uma nova subjetividade na qual os indivíduos assumam responsabilidades de lidar com questões coletivas antes do Estado [...]". Trata-se de desenvolver, "[...] em especial nas comunidades com problemas sociais, o seu 'capital social', ou seja, a capacidade da coletividade se mobilizar para resolver suas dificuldades $[\ldots]$ ”.

No âmbito do PSE, essa perspectiva se reflete na noção de que os educandos não devem se preocupar somente com a saúde individual, mas também com a de seus pares. Nesse Programa, a perspectiva de promoção da solidariedade pode ser identificada quando se afirma que o “[...] trabalho 
conjunto entre escola e equipe de saúde pode trazer novos sentidos para a produção da saúde, construindo redes de produção de saberes e de solidariedade entre profissionais e comunidade" (BRASIL, 2011a, p. 17). Respaldado ainda em valores como "respeito mútuo" e "cooperação", o Programa revela a intenção de formar redes de colaboração mútua para a resolução de problemas de saúde da população (BRASIL, 2011a, p. 43).

Dois dos principais pilares do modelo de gestão intersetorial e compartilhada do PSE são a interdisciplinaridade e a participação de toda a comunidade. Como dispõe o art. $3^{\circ}$ do Decreto n. 6.286/2007, o PSE “[...] constitui estratégia para a integração e a articulação permanente entre as políticas e ações de educação e de saúde, com a participação da comunidade escolar, envolvendo as equipes de saúde da família e da educação básica" (BRASIL, 2007).

Assim, no âmbito do PSE, as parcerias não são estabelecidas somente entre os Ministérios, mas entre os diversos atores envolvidos nessa política. Logo, o Programa prevê parceria com os jovens beneficiários - na perspectiva de promoção do protagonismo juvenil -, professores e comunidade, com o intuito de catalisar o desenvolvimento local e o trabalho em rede (BRASIL, 2011a). Na perspectiva do PSE, compreende-se que a "[...] articulação intersetorial das redes públicas de saúde e de educação e das demais redes sociais para o desenvolvimento das ações do PSE [...] deve propiciar a sustentabilidade das ações a partir da conformação de redes de corresponsabilidade" (BRASIL, 2013a, p. 4).

Dessa maneira, no PSE, a “[...] responsabilidade de promover a saúde dos escolares, além de ser um compromisso do setor saúde, passa a ser definida como processo de conscientização da comunidade para atuar na melhoria da qualidade de vida" (VIEIRA, 2013, p. 27). Segundo Vieira (2013, p. 16), a construção de redes de corresponsabilidade fomentada pelo PSE estimularia “[...] a participação mais ativa da comunidade no cotidiano dos sistemas de ensino e saúde [...]”.

Ademais, no processo de elaboração do projeto municipal do PSE entende-se que todos deveriam trabalhar como parceiros - secretarias, programas, sociedade civil organizada, conselhos locais, organizações não governamentais, pastorais, entre outros - para criação e potencialização das iniciativas existentes. Trabalhar na perspectiva do diálogo, da participação dos diferentes atores sociais e da formação de redes de colaboração seria fundamental para a redução das vulnerabilidades e promoção da saúde de crianças, adolescentes e jovens (BRASIL, 2010). 


\section{O compartilhamento dos princípios da teoria do "Capital Humano" no PSE}

A teoria do "capital humano" foi exposta na década de 1960, tendo como um de seus principais idealizadores o economista estadunidense Theodore William Schultz. Ao estudar a rápida recuperação da economia japonesa no período pós-guerra, esse economista concluiu que o investimento em "capital não humano", como em usinas de aço e fábricas, por exemplo, não explicava o desenvolvimento econômico de um país, mas sim os investimentos em "capital humano" realizados nas áreas de:

[...] 1) recursos relacionados a saúde e serviços; 2) treinamento realizado no local do emprego; 3) educação formalmente organizada; 4) programas de estudos para os adultos que não se acham organizados em firmas; 5) migração de indivíduos e de famílias. (SCHULTZ, 1973, p. 42).

Dessa forma, para Schultz (1973), a realização desses tipos de investimentos melhoraria a qualidade do esforço humano, agregando-lhe maior capacidade produtiva, que, por consequência, poderia promover o desenvolvimento econômico dos países. Por tais aspectos, segundo essa teoria, o investimento em "capital humano" seria a chave para o crescimento econômico e para a abundância. Por isso, diferentemente das demais teorias neoliberais, a teoria do "capital humano" apoia certa quantia de investimento público-estatal no setor social, especialmente em áreas como a educação básica e a pesquisa.

Compartilhando dos pressupostos da teoria do "capital humano", o neoliberalismo de Terceira Via advoga que a modernização do welfare state deveria ser promovida paralelamente a programas de desenvolvimento da sociedade civil. Portanto, de acordo com Giddens (1998, p. 127-128), em "[...] lugar do welfare state deveríamos considerar o Estado do investimento social [...]". No âmbito desse modelo de Estado, o governo teria um papel de grande relevância, "[...] investindo nos recursos humanos e na infra-estrutura [sic] necessária para o desenvolvimento de uma cultura empresarial" (GIDDENS, 1998, p. 109).

De acordo com as formulações de Giddens, não seria papel do governo financiar serviços à população, mas tão somente auxiliá-la em sua preparação para a inserção no mercado de trabalho, de forma a contribuir, em última instância, para o crescimento e o desenvolvimento econômico. Por isso, a forma mais adequada de investimento social a ser adotada pelo Estado seria a de investimento em "capital humano". Esse tipo de investimento teria grande importância na preparação para o trabalho e na diminuição das taxas de desemprego. Dessa maneira, as políticas de preparação para o trabalho deveriam fazer parte da agenda do governo de Terceira Via. A ideia central desse pensamento advoga 
que o investimento em "capital humano" aumentaria as possibilidades pessoais para o aproveitamento das oportunidades oferecidas pelo mercado, o que seria de extrema relevância para que a sociedade civil se tornasse cada vez mais autônoma perante o Estado.

No modelo de welfare positivo, portanto, a diretriz seria o investimento em "capital humano," sempre que possível, no lugar do fornecimento de sustento econômico. Nas palavras de Giddens (1998, p. 133), os gastos estatais com o welfare deveriam ser diminuídos e "[...] desviados tanto quanto possível para o investimento em capital humano". Aliás, esse tipo de investimento consistiria na tarefa mais importante no processo de modernização da política a ser empreendido pela Terceira Via.

Vale destacar que, para a Terceira Via, os investimentos pessoais em "capital humano" (como em educação e saúde) seriam a situação ideal, livrando assim o Estado do dever de oferecer esses tipos de recursos. Por isso, considera-se que em “[...] vez de se assentar em benefícios incondicionais, as políticas deveriam ser orientadas para incentivar a poupança, o uso de recursos educacionais e outras oportunidades de investimento pessoal" (GIDDENS, 1998, p. 135).

Frente a inevitabilidade do investimento estatal em setores sociais, a recomendação é para que estes sejam feitos em parcerias com outras instituições e empresas, pois, mediante tais parcerias, o Estado seria capaz de investir em "capital humano", na forma de empregos, saúde e educação, por exemplo, e, ao mesmo tempo, de se desobrigar do pagamento direto dos benefícios sociais (CHAUÍ, 1999). Acrescenta esta autora que o Estado " [...] faz parcerias com empresas de saúde e se desobriga à saúde pública gratuita; o Estado faz parcerias com empresas de educação e se desobriga à educação pública gratuita etc.” (CHAUÍ, 1999, p. 7).

Torna-se evidente que os incentivos à formação da "sociedade civil ativa" e do "Terceiro Setor", "capital humano" e "capital social" têm por objetivo preparar os sujeitos para enfrentarem a realidade em que o Estado não supre as demandas e necessidades da população. A efetivação de investimentos dessa natureza é uma tentativa de formar uma sociedade autossuficiente e independente da atuação do Estado, instituição que, cada vez mais, se assumiria como indutora do progresso individual, responsável por criar e manter condições favoráveis à geração e aproveitamento de oportunidades (MARTINS, 2009).

As políticas internacionais e nacionais de educação e saúde na escola estão incluídas nas agendas políticas direcionadas ao desenvolvimento socioeconômico de países, especialmente os países pobres. Isso dá respaldo à compreensão de que a teoria do "capital humano" é um dos pilares teóricoideológicos que sustenta tal política internacional e nacionalmente. 
A América Latina é exemplar nesse sentido: investimentos em educação e saúde são apregoados por organizações internacionais, especialmente pelo Banco Mundial, como molas propulsoras para o desenvolvimento socioeconômico. Na perspectiva da ONU, por exemplo, investimentos em saúde do trabalhador são importantes, tendo em vista que as doenças ocupacionais seriam prejudiciais não somente aos trabalhadores e suas famílias, mas também à sociedade, “[...] devido ao enorme custo gerado, particularmente no que diz respeito à perda de produtividade e à sobrecarga dos sistemas de seguridade social” (ORGANIZAÇÃO MUNDIAL DAS NAÇÕES UNIDAS, 2013, p. 1).

Em 2008, o Programa Saúde na Escola foi incorporado à proposta do plano "Mais Saúde Direito de Todos - 2008-2011” (BRASIL, 2008), no qual é possível identificar a proposição de investimentos em políticas de saúde com vistas ao desenvolvimento econômico brasileiro. Nas palavras do Plano, a saúde deveria ser entendida não somente como uma política social, mas sobretudo "[...] como parte integrante do desenvolvimento econômico do país" (BRASIL, 2008, p. 5), porque um "[...] país somente pode ser denominado 'desenvolvido' se seus cidadãos forem saudáveis, o que depende tanto da organização e do funcionamento do sistema de saúde quanto das condições gerais de vida associadas ao modelo de desenvolvimento vigente" (BRASIL, 2008, p. 8).

Ainda conforme o referido documento, a política de saúde teria papel fundamental no desenvolvimento do Brasil porque é "[...] parte da política social e do sistema de proteção social e fonte de geração de riqueza para o País" (BRASIL, 2008, p. 9). Assim sendo, antes de serem entendidos como um fardo para o orçamento público, os investimentos em saúde deveriam ser vistos como "[...] parte constitutiva da estratégia de desenvolvimento e como uma frente de expansão para um novo padrão de desenvolvimento comprometido com o bem-estar social", uma vez que a saúde "[...] contribui tanto para os direitos de cidadania quanto para a geração de investimentos, inovações, renda, emprego e receitas para o Estado brasileiro" (BRASIL, 2008, p. 9).

No principal documento orientador do Programa Saúde na Escola (BRASIL, 2011a, p. 18), as ações de educação e saúde na escola estão articuladas à ideologia do desenvolvimentismo, com enfoque na promoção do "desenvolvimento sustentável". Segundo esse documento, as estratégias concernentes ao componente II do PSE - "Promoção e Prevenção à Saúde" - devem ser abordadas a partir de alguns temas específicos, dentre os quais encontra-se o da “[...] Promoção da saúde ambiental e desenvolvimento sustentável” (BRASIL, 2011a, p. 18). Recomenda-se nessa linha de ação a realização de atividades de sensibilização, responsabilização e intervenção na perspectiva do cuidado consigo mesmo e com o ambiente escolar. 
Investimentos em “capital humano" e em “capital social”, conforme explica Motta (2011), são recomendações das organizações internacionais para o alívio da pobreza e das tensões sociais disseminadas a partir das últimas décadas do século XX. Assim, considerando-se o fato de que o PSE vem atuando na promoção do "capital humano" e do "capital social", pode-se apreender que esse Programa é um mecanismo de administração e alívio da pobreza no contexto da sociabilidade brasileira e um importante ator no projeto conservador contemporâneo de forjar um capital de "face mais humana" (MOTTA, 2011, p. 42).

\section{A perspectiva do protagonismo juvenil no PSE}

Por intermédio da análise das fontes primárias, identificou-se que os incentivos à formação da "sociedade civil ativa" e do "Terceiro Setor", à promoção do "capital social" e ao compartilhamento dos princípios da teoria do "capital humano" se expressam no Programa Saúde na Escola, principalmente pelo ideário do protagonismo juvenil fomentado pelas estratégias de empoderamento.

Políticas focalizadas na população juvenil começaram a ser desencadeadas a partir do final da década de 1990 e início dos anos de 2000. Orientadas ao enfrentamento de problemas como os relacionados à saúde, segurança e trabalho, por exemplo, causas da condição de vulnerabilidade social da população jovem, as políticas para a juventude visam à população juvenil em condição de risco social (fundamentalmente àquela em situação de pobreza) para promoção de controle social. Nesse sentido, as iniciativas governamentais em relação aos jovens estão centradas, predominantemente, em jovens pobres (SPOSITO; CARRANO, 2003).

No discurso das políticas de juventude, consta a noção de que as soluções para a superação da condição de vulnerabilidade de jovens pobres poderiam ser encontradas no âmbito da própria população juvenil em vulnerabilidade. Isto porque, para esse ideário, tais jovens comportariam, intrinsecamente, a capacidade de identificar problemas e apontar soluções para as condições de vulnerabilidade social.

Essa noção alude ao conceito de "protagonismo juvenil", que se tornou recorrente nos discursos governamentais e de organizações internacionais, especialmente após a segunda metade dos anos 1990. $\mathrm{Na}$ perspectiva do protagonismo juvenil, os jovens deveriam ser compreendidos como atores sociais capazes de atuar como agentes de seu próprio desenvolvimento e de seus pares. Os jovens deveriam se distanciar da passividade social e assumir uma atitude ativa mediante as suas condições de vida e de sua comunidade. Pode-se entender, portanto, o protagonismo juvenil como um discurso que busca 
suscitar nos jovens a motivação necessária para atuarem na mudança social, com base na valorização do indivíduo (SOUZA, 2006). Complementa Costa (2007, p. 1):

[...] quando o adolescente, individualmente ou em grupo, se envolve na solução de problemas reais; atuando como fonte de iniciativa, liberdade e compromisso; temos, diante de nós, um quadro de participação genuína no contexto escolar ou sóciocomunitário[sic], o qual pode ser chamado de protagonismo juvenil.

Ainda tratando da concepção de protagonismo juvenil, Costa $(2007$, p. 1), esclarece que o “[...] centro da proposta é que, por meio da participação ativa, construtiva e solidária, o adolescente possa se envolver na solução de problemas reais na escola, na comunidade e na sociedade". Somente por meio da participação ativa, "de fato autêntica e não simbólica, decorativa ou manipulada", no âmbito das políticas, o jovem poderia passar a se reconhecer como protagonista (COSTA, 2007, p. 1). Assim, o protagonismo juvenil pode ser compreendido como "um discurso que prescreve sobre a participação política da juventude" (SOUZA, 2006, p. 20).

Para que os jovens pudessem atuar como protagonistas, além da promoção de sua participação efetiva, seriam necessárias estratégias de instrumentalização e empoderamento desta população (SOUZA, 2006). Em resumo, a participação ativa dos jovens seria um meio para o desenvolvimento do protagonismo juvenil que, por sua vez, mediaria a superação das desigualdades sociais e da pobreza. Em outras palavras, a superação das manifestações da "questão social", como as desigualdades e a pobreza, poderia e deveria ser empreendida pelos próprios pobres.

Como parte das políticas para a juventude na contemporaneidade, as políticas internacionais e nacionais de educação e saúde na escola compartilham da perspectiva do protagonismo juvenil, compreendendo-o como fundamental à promoção da saúde e qualidade de vida. No âmbito do Programa Saúde na Escola, o discurso de participação dos jovens e promoção do protagonismo juvenil é estratégia destacada. Segundo o documento orientador do Programa, "[...] as ações de promoção da saúde visam a garantir oportunidade a todos os educandos de fazerem escolhas mais favoráveis à saúde e de serem, portanto, protagonistas do processo de produção da própria saúde, buscando melhoria de sua qualidade de vida" (BRASIL, 2011a, p. 17).

No Componente III do PSE, que dispõe sobre a formação de agentes de educação e saúde na escola, consta a "Formação de Jovens Protagonistas para o PSE/SPE por meio da metodologia de educação de pares”, como caminho para “[...] a valorização do jovem como protagonista na defesa dos direitos à saúde" (BRASIL, 2011a, p. 18). Além disso, segundo o discurso veiculado pelo PSE: 
A inclusão dos temas nos projetos político-pedagógicos também facilita o protagonismo dos educandos, apontando para um processo importante de autocuidado. Falar e trabalhar pedagogicamente os temas da alimentação, visão, audição, práticas corporais e outros aproximam os educandos da ação e desperta o interesse deles com suas próprias condições de saúde e riscos. (BRASIL, 2011a, p. 16).

Compreende-se ainda que os conhecimentos relativos à articulação entre educação e saúde potencializariam “[...] o desenvolvimento de ações que privilegiam a dimensão educativa do cuidado à saúde, do cuidado de si, do outro e do ambiente [...]", ocasionando "[...] efeitos no desenvolvimento saudável e protagonismo do educando e da comunidade onde vive, permitindo que realize opções que melhorem sua qualidade de vida" (BRASIL, 2013a, p. 9).

Nesse sentido, assinala-se no âmbito do PSE que as

[...] avaliações das condições de saúde precisam envolver de forma protagonista os educandos, é preciso que eles saibam o que está acontecendo e para que servem as ações realizadas, as atividades são melhores sucedidas quando se convertem em processos de educação em saúde. Não basta detectar problemas, é importante ter compromisso com a produção de autonomia e de autocuidado dos escolares. (BRASIL, 2013a, p. 9).

Observa-se, dessa maneira, que o sentido e o significado do conceito de participação veiculado pelo ideário do protagonismo juvenil, presente no discurso hegemônico disseminado por organizações internacionais (inclusive no campo das políticas de educação e saúde na escola) está articulado à perspectiva de resolução de conflitos sociais. Esse conceito de participação - resultante da apropriação e ressignificação neoliberal - seria uma importante estratégia de combate às desigualdades sociais e um “[...] meio de evitar o descontrole e assegurar a coesão social” (SOUZA, 2006, p. 9). Diferentemente do conceito de participação defendido e exercido no contexto da década de 1980, por exemplo, veiculado à contestação da ordem posta e à reivindicação por direitos sociais.

Esclarece Souza (2006, p. 9), que “[...] o jovem protagonista é invariavelmente lembrado como 'ator principal' no cenário público, posição de destaque que supõe algum tipo de ação política, [...] uma ação política despida da luta e transformada em atuação social" (SOUZA, 2006, p. 9, grifos do autor). No âmbito do discurso do protagonismo juvenil, a mudança social é compreendida como "atividade direta do indivíduo" e "alteração imediata e quantificável de uma situação específica, considerada negativa, e que atinge um número determinado de pessoas” (SOUZA, 2006, p. 11). Veicula-se, assim, o “ativismo privado" como meio de mudança social (SOUZA, 2006, p. 11).

Essa perspectiva pode ser reconhecida no Programa Saúde na Escola, na medida em que este afirma ter a escola potencial singular para a formação de sujeitos “[...] autônomos e críticos, capazes de 
compreender a realidade e modificá-la do lugar que ocupam, ou seja, aptos a fazer uma reflexão acerca dos problemas da comunidade e a propor ações para resolvê-los, a partir de suas perspectivas" (BRASIL, 2011a, p. 17). Observa-se, portanto, que o apelo à participação ativa da sociedade civil realizado pelo ideário da Terceira Via e identificado nas políticas públicas de educação e saúde na escola não ultrapassa os limites da resolução dos problemas individuais e locais da comunidade.

Em seu sentido mais amplo, considera-se que, para além da transmissão de informações, cabe à educação a tarefa de formar sujeitos autônomos e criativos (tendo em vista que a criatividade é uma capacidade básica para o desenvolvimento das funções psíquicas superiores) e ativos em saúde. O problema está na forma com que o capital autonomiza esses sujeitos, ao torná-los autônomos, criativos e saudáveis em um meio um cenário de valorização de capital, de legitimação do afastamento do Estado de suas funções sociais e de amenização das manifestações da "questão social". Em suma, entende-se que o problema não está no processo de autonomização dos sujeitos em si, mas sim na apropriação desse processo para fins, imediatos ou não, estreitamente ligados aos interesses de manutenção do sistema capitalista.

Mediante tais aspectos, entende-se que o discurso do protagonismo juvenil, apesar de defender a participação ativa do jovem na esfera política (o que seria basilar do ponto de vista da concretização e ampliação dos direitos sociais), uma vez que canaliza essa participação ativa dos jovens para o âmbito da resolução de conflitos sociais (como os relativos à saúde pública), pode levar à legitimação do afastamento do Estado de suas funções sociais e, ao mesmo tempo, afastar do campo ideológico social a necessidade da revolução para a superação de tais conflitos, já que veicula a ideia de que os problemas sociais podem ser resolvidos dentro da própria lógica capitalista, por intermédio de iniciativas locais e individuais.

\section{Considerações finais}

Com o constructo da Terceira Via, o neoliberalismo se aperfeiçoou, tornando-se poderosa referência ideológica para a ação política, com a renovação de estratégias de consenso, conformação e dominação do capital. Mediante a propagação da racionalidade ideológica conservadora, que defende ser o capital uma ordem racionalmente administrável, a Terceira Via vem executando seu projeto educacional direcionado à formação de cidadão de novo tipo, ativo, autônomo e, sobretudo, preparado para enfrentar os desafios da realidade contemporânea, na qual a responsabilidade pelo bem-estar social passou a ser compartilhada por toda a sociedade civil. 
Apesar de estratégias de regulação e controle social alinhadas ao neoliberalismo de Terceira Via serem adotadas com a promessa de compatibilizar economia de mercado e justiça social - tal como o Programa Saúde na Escola -, observa-se o aprofundamento da crise social e a exponenciação da "questão social". Este quadro atual demonstra a incapacidade do modo de produção social capitalista de dar respostas efetivas e definitivas às manifestações da "questão social", como as que se expressam em âmbito escolar e são alvos das políticas de educação e saúde na escola. As expressões da "questão social" manifestadas na escola pública brasileira não podem ser solucionadas nos limites das políticas educacionais (ou por estas em articulação com as políticas de saúde), exatamente porque tais expressões não são derivadas da insuficiência das políticas sociais em curso, e sim das contradições próprias do processo de acumulação e expansão do capital.

Considerando-se o exposto, conclui-se que as políticas de educação e saúde na escola e, de forma mais específica, o PSE - ao propor o enfrentamento das expressões da "questão social" por intermédio das ideologias da "sociedade civil ativa", do "capital social" e do "capital humano" podem, quando muito, amenizar as contradições entre capital e trabalho (materializadas, por exemplo, na forma de problemas de saúde), mas jamais solucioná-las em definitivo. Assim, programas educacionais de assistência, como o Programa Saúde na Escola, somente podem exercer papel amenizador frente às manifestações da "questão social".

Em resposta ao problema de pesquisa enunciado no início deste trabalho, com os subsídios obtidos pela análise das fontes primárias, pode-se afirmar que a função social do PSE é colaborar com a disseminação da racionalidade ideológica conservadora, compatível com a edificação de um novo padrão de sociabilidade no Brasil, via formação de subjetividades ativas em saúde, contribuindo também para amenizar as manifestações da "questão social" e para que a força de trabalho mantenha-se em condições de atender às necessidades de exploração capitalista.

Entretanto, é importante não perder de vista que, por um lado, o PSE opera no projeto de formação do sujeito ativo, limitando-se a ofertar serviços mínimos de educação e saúde para a amenização das desigualdades sociais e da pobreza, e, por outro, inscreve-se na tendência da garantia do direito e melhoria da qualidade dos serviços básicos de educação e saúde. Dito de outro modo, o fato de as ações contemporâneas de educação e saúde na escola serem partes da nova modalidade de políticas neoliberais de resposta do capital às expressões da "questão social", direcionada ao estabelecimento e legitimação de um novo consenso, controle e regulação social, não as desclassificam como importantes iniciativas no âmbito da luta democrática por direitos. 


\section{REFERÊNCIAS}

BEHRING, Elaine R. Política social no capitalismo tardio. 3. ed. São Paulo - SP: Cortez, 2007. v. 1.

BRASIL. Decreto $n^{\circ}$ 6.286, de 5 de dezembro de 2007. Institui o Programa Saúde na Escola - PSE, e dá outras providências. Diário Oficial [da] República Federativa do Brasil. Brasília, DF, 6 dez. 2007, p. 2. Disponível em: <http://www.planalto.gov.br/ccivil_03/_ato20072010/2007/decreto/d6286 .htm>. Acesso em: 30 ago. 2015.

BRASIL. Mais Saúde - Direito de Todos 2008-2011. Brasília, DF: Ministério da Saúde, 2008. Disponível em: <http://bvsms.saude.gov.br/bvs/publicacoes/mais_saude_direito_todos_2ed.pdf $>$. Acesso em: 30 ago. 2015.

BRASIL. Orientações para elaboração do Projeto Municipal - PSE. Brasília, DF: Ministério da Saúde, 2010. Disponível em:

$<$ http://189.28.128.100/dab/docs/geral/orientacao_elaboracao_projetoPSE.pdf $>$. Acesso em: 30 ago. 2015.

BRASIL. Passo a Passo PSE Programa Saúde na Escola: Tecendo caminhos da Intersetorialidade. Brasília, DF: Ministério da Saúde, 2011a. Disponível em:

<http://189.28.128.100/dab/docs/legislacao/passo_a_passo_pse.pdf>. Acesso em: 30 ago. 2015.

BRASIL. Plano de Ações Estratégicas para o Enfrentamento das Doenças Crônicas NãoTransmissíveis (DCNT) no Brasil 2011-2022. Brasília, DF: Ministério da Saúde. 2011b. Disponível em: <http://actbr.org.br/uploads/conteudo/918_cartilha_dent.pdf>. Acesso em: 30 ago. 2015.

BRASIL. Decreto n 7 7.492, de 02 de junho de 2011 - Institui o Plano Brasil Sem Miséria. Brasília, DF, 2011c. Diário Oficial [da] República Federativa do Brasil, Poder Executivo, Brasília, DF, 3 jun. 2011, p. 6. Disponível em: <http://www.planalto.gov.br/ccivil_03/_Ato20112014/2011/Decreto/D74 92.htm>. Acesso em: 30 ago. 2015.

BRASIL. Programa Saúde na Escola: Manual Instrutivo. Brasília, DF: Ministério da Saúde/ Ministério da Educação, 2013a. Disponível em:

$<$ http://www.pmf.sc.gov.br/arquivos/arquivos/pdf/19_06_2013_16.21.18.880166244cb983df2c85e0bc 746a73b.pdf>. Acesso em: 30 ago. 2015.

BRASIL. Saúde da Família: Passo a Passo do Departamento de Atenção Básica. Brasília, DF: Ministério da Saúde, 2013b. Disponível em: <http://189.28.128.100/dab/docs/portaldab/documentos/ passo_a_passo_dab.pdf>. Acesso em: 30 ago. 2013.

CHAUÍ, Marilena. Fantasia da Terceira Via. Jornal Folha de São Paulo, São Paulo, p. 01 - 01, 19 dez. 1999. Data de publicação: 19 dez. 1999. Disponível em: <http://www.oocities.org/athens/aegean/ 9837/chauiterceiravia.html>. Acesso em: 30 ago. 2015.

COSTA, Antonio C. G. C. O adolescente como protagonista juvenil. Protagonismo Juvenil, São Paulo, p. 01 - 01, 20 jun. 2007. Data de publicação: 20 jun. 2007. Disponível em: 
$<$ http://protagonismojuvenil.blogspot.com.br/2007/06/o-adolescente-como-protagonista.html>. Acesso em: 30 ago. 2015.

CURY, Carlos Roberto Jamil. Educação e contradição: elementos metodológicos para uma teoria crítica do fenômeno educativo. São Paulo: Cortez, 1986.

GIDDENS, Anthony. A Terceira Via: reflexões sobre o impasse político atual e o futuro da socialdemocracia. 5. ed. Rio de Janeiro/São Paulo: Record, 1998. v. 1.

GROPPO, Luís A.; MARTINS, Marcos F. Terceira Via e políticas educacionais: um novo mantra para a educação. RBPAE, Porto Alegre, v. 24, n. 2, p. 215-233, 2008.

MARTINS, André S. Burguesia e a nova sociabilidade: estratégias para educar o consenso no Brasil contemporâneo. 2007. 293f. Tese (Doutorado em Educação) - Universidade Federal Fluminense, Niterói, 2007.

MARTINS, André S. Os fundamentos do projeto neoliberal: formulações para educar a sociabilidade. In: MARTINS, André S (Org.). A direita para o social: a educação da sociabilidade no Brasil contemporâneo. Juiz de Fora: UFJF, 2009, v. 1, p. 33-58.

MONTAÑO, Carlos. O projeto neoliberal de resposta à "questão social" e a funcionalidade do "terceiro setor”. Lutas Sociais, São Paulo, v. 1, n. 8, p. 53-64, 2002.

MONTAÑO, Carlos; DURIGUETTO, Maria L. 3. ed. Estado, classe e movimento social. São Paulo: Cortez, 2011. v. 1.

MOTTA, Vânia C. Educação e capital social: orientações dos organismos internacionais para as políticas públicas de educação como mecanismos de alívio à pobreza. In: ANDRADE, Juarez; PAIVA, Lauriana G. (Org.). As políticas públicas para a educação no Brasil contemporâneo: limites e contradições. Juiz de Fora: UFJF, 2011, v. 1, p. 36-55.

NETTO, José P. Introdução ao estudo do método de Marx. São Paulo: Expressão Popular, 2011.

NETTO, José P.; BRAZ, Marcelo. Economia política: uma introdução crítica. São Paulo: Cortez, 2006.

NEVES, Lúcia M. W. (Org.). A nova pedagogia da hegemonia: Estratégias do capital para educar o consenso. São Paulo: Xamã, 2005. v. 1.

NEVES, Lúcia M. W. Politicas sociales contemporáneas: tesis para discusión. Revista Argentina de Educación, Buenos Aires, v. 30, n. 30, p. 7-27, 2008.

ORGANIZAÇÃO MUNDIAL DAS NAÇÕES UNIDAS. OIT: um trabalhador morre a cada 15 segundos por acidentes ou doenças relacionadas ao trabalho. São Paulo, 24 abr. 2013. 24 abr. 2013. Disponível em: <http://www.onu.org.br/oit-um-trabalhador-morre-a-cada-15-segundos-por-acidentesou-doencas-relacionadas-ao-trabalho/>. Acesso em: 30 ago. 2015. 
SCHULTZ, Theodore W. O capital humano: investimentos em educação e pesquisa. Rio de Janeiro -: Zahar, 1973. v. 1.

SOUZA, Regina M. O discurso do protagonismo juvenil. 2006. 351f. Tese (Doutorado em Sociologia) - Universidade de São Paulo, Faculdade de Filosofia, Letras e Ciências Humanas, São Paulo, 2006.

SPOSITO, Marília P.; CARRANO, Paulo C. R. Juventude e políticas públicas no Brasil. Revista Brasileira de Educação, São Paulo, v. 1, n. 24, p. 16-39, 2003.

VIEIRA, Ana C. C.; VIEIRA, Valéria S. A necessidade de capacitação dos profissionais do Programa Saúde na Escola para inclusão de orientações posturais preventivas no âmbito escolar. Ciência em Tela, Rio de Janeiro, v. 4, n. 2, p. 1-15, 2011.

VIEIRA, Maria E. M. Programa Saúde na Escola: a intersetorialidade em movimento. 2013. 94f. Dissertação (Mestrado em Psicologia) - Universidade de Brasília, Instituto de Psicologia, Brasília, 2013. 
The social function of Programa Saúde na

Escola: formation for new capital sociability?

\begin{abstract}
This paper analyzes the social function of the School Health Program (PSE) based on a bibliographical and documentary study, which used a historical materialist methodology. It finds that this program is articulated to three components of the "Third Way" neoliberal educational project: the notion of "active civil society" and the "third sector" project; the ideology of "social capital" and the theory of "human capital". The study found that the social function of the School Health Program is to collaborate in the spread of conservative ideological reasoning, which is compatible with the construction of a new standard of sociability in Brazil, through formation of active subjectivities in healthcare. The program also serves to mitigate expressions of the "social question" and maintain a workforce that can meet the needs of capitalist exploitation.
\end{abstract}

Keywords: Public education policies. Healthcare policy. School Health Program.

Aline Fabiane Barbieri

E-mail: alinefb_90@yahoo.com.br

Amélia Kimiko Noma

E-mail: aknoma@uem.br
La función social del Programa Salud en la Escuela (PSE): formación para una nueva sociabilidad del capital

\section{Resumen}

Este estudio analiza la función social del Programa Salud en la Escuela (PSE), basado en el estudio bibliográfico y documental, a partir del método del materialismo histórico. Se considera que el PSE se articula a tres componentes del proyecto educativo neoliberal de la tercera vía: la noción de "sociedad civil activa" y el proyecto "Tercer Sector", la ideología del "capital social" y la teoría del "capital humano". Se afirma que la función social del PSE es colaborar con la difusión de la racionalidad ideológica conservadora, apoyada en la construcción de un nuevo patrón de sociabilidad en Brasil, mediante la formación de subjetividades activas en materia de salud, así como actuar en la mitigación de las expresiones de la "cuestión social" y el mantenimiento de la fuerza de trabajo capaz de satisfacer las necesidades de la explotación capitalista.

Palabras claves: Las políticas públicas de educación. Política de salud. Programa de Atención a la Salud en la Escuela.

Enviado em: 31/08/2015

Versão final recebida em: 25/09/2016

Aprovado em: 25/09/2016 